\title{
FORMULATION AND PHYSICAL CHARACTERIZATION OF CURCUMIN NANOPARTICLE TRANSDERMAL PATCH
}

\author{
SURYANI ${ }^{*}$, W. A. ODE SITTI MUSNINA ${ }^{2}$, RUSLIN ${ }^{1}$, MICHRUN NISA ${ }^{3}$, RIMA APRIANTI ${ }^{1}$, MARGANITA HASANAH ${ }^{1}$, \\ FIRDA RAHMANIA PUTRI ${ }^{1}$, ANDI NAFISAH TENDRI ADJENG ${ }^{1}$, NANI YUNIAR ${ }^{4}$, MUHAMAD HANDOYO \\ SAHUMENA ${ }^{1}$, MUHAMMAD ASWAN ${ }^{1}$
}

1Department of Pharmacy, Faculty of Pharmacy, Halu Oleo University, Kendari, Sulawesi Tenggara, Indonesia, ${ }^{2}$ Department of Pharmacy, Faculty of Mathematics and Science, Tadulako University, Palu, Sulawesi Tengah, Indonesia, ${ }^{3}$ Sekolah Tinggi Ilmu Farmasi, Makassar, Sulawesi Selatan, Indonesia, ${ }^{4}$ Faculty of Public Health, Halu Oleo University, Kendari, Sulawesi Tenggara Email: suryanisuere@gmail.com

Received: 05 Jul 2019, Revised and Accepted: 11 Oct 2019

ABSTRACT

Objective: This study was conducted to formulate curcumin nanoparticles transdermal patches and to evaluate their physical characterization.

Methods: Curcumin nanoparticles transdermal patches were formulated by the casting evaporation method. Transdermal patches were made using combinations of hydroxypropyl methylcellulose (HPMC) and ethyl cellulose (EC) at ratios of 4.5:1.5 for Formula 1 (F1), 4:1 for Formula 2 (F2), 3.5:1.5 for Formula 3 (F3), 3:2 for Formula 4 (F4), and 2.5:2.5 for Formula 5 (F5). Physical characterization evaluation (organoleptic properties, pH, weight uniformity, thickness uniformity, percent moisture content, and tensile strength) was then performed. The permeation of curcumin nanoparticles into the skin was evaluated using Franz diffusion cells.

Results: Curcumin nanoparticles transdermal patches could be formulated by the casting evaporation method with the organoleptic properties characterized as smooth, dry, yellow in color, having menthol odor, and transparent. The $\mathrm{pH}$ values ranged between 5.0 and 6.0. The thickness of the patches ranged from 0.1 to $0.2 \mathrm{~mm}$. The average of the patches' weight was $0.7 \mathrm{~g}$, and the percent moisture content ranged from 1.0 to $6.0 \%$. The tensile strength values were 1.0 to $2.0 \mathrm{~N} / \mathrm{mm}$. Curcumin nanoparticles could penetrate into the skin with flux values being $1.271 \mu \mathrm{g}$. $\mathrm{cm}^{-2}$ (F1), 0.938 $\mu \mathrm{g} . \mathrm{cm}^{-2}$ (F2), $0.775 \mu \mathrm{g} . \mathrm{cm}^{-2}$ (F3), $0.837 \mu \mathrm{g} . \mathrm{cm}^{-2}$ (F4), and $0.569 \mu \mathrm{g} . \mathrm{cm}^{-2}$ (F5).

Conclusion: All patches met the requirement of the physical characterization for the transdermal patch.

Keywords: Formulation, Physical characterization, Curcumin Nanoparticles, Transdermal patch

(C) 2019 The Authors. Published by Innovare Academic Sciences Pvt Ltd. This is an open access article under the CC BY license (http://creativecommons.org/licenses/by/4.0/) DOI: http://dx.doi.org/10.22159/ijap.2019v11i6.34780

\section{INTRODUCTION}

Curcumin is a polyphenolic compound that can be found in turmeric Curcumin exerts several activities, including anti-inflammatory activity [1]

The potency of curcumin as an anti-inflammatory drug is limited because it has low bioavailability in the blood because of its poor solubility in aqueous media and because curcumin oral administration undergoes first-pass metabolism in the gastrointestinal tract [2]. To overcome such limitations, curcumin can be administrated through the transdermal route.

Transdermal drug delivery systems are the delivery of drugs through various layers of the skin. One of the limitations of the transdermal route is that only a few drugs can penetrate into the skin [3]. One way to overcome this limitation is by formulating drugs as nanoparticles. In our previous work, we formulated curcumin nanoparticles from chitosan polymers and tripolyphosphate [4] and provided good characteristics of curcumin nanoparticles. The use of chitosan could affect the permeation rate of active agents [5].

One example of transdermal preparation is a patch. Patch preparations have several advantages, namely greater safety and convenience in usage, painless usage, and higher precision in dosage than other transdermal preparations [6]

The research that was conducted by Chauhan SB [7] showed that the combination of hydrophilic and hydrophobic polymer could result good physical characteristics and increase the effectivity the of patch. Based on the description above, in this research, we formulated curcumin nanoparticles transdermal patches using the evaporation casting method by combining HPMC (water-soluble polymer) and EC (water-insoluble polymer) at various ratios and evaluated their physical characterization and the permeation of curcumin nanoparticles into the skin by using Frans diffusion cells.

\section{MATERIALS AND METHODS}

Materials

Curcumin nanoparticles were taken from the Laboratory of Pharmaceutics, Faculty of Pharmacy, Halu Oleo University, Kendari, Indonesia. Curcumin nanoparticles were formulated from chitosan and tripolyphosphate (the reinforcement ionic gelation method) [4]. Other materials included HPMC (ShimEtsu, Japan), EC n10 (Hercules, USA),chloroform (Merck, Germany), $\mathrm{NaOH}$ (Brataco, Indonesia), polyethylene glycol 400 (PEG 400) (Merck, Germany), dichloromethane (Merck, Germany), potassium dihydrogen phosphate (Merck, Germany), ethanol (Brataco, Indonesia), menthol (Brataco, Indonesia), white rats (Rattus Norvegicus), and distilled water (Brataco, Indonesia)

\section{Methods}

Formulation of curcumin nanoparticles transdermal patches

Transdermal patches of curcumin nanoparticles were made by the evaporation casting method. Five formulas of curcumin nanoparticles transdermal patches were formulated combinations of HPMC and EC polymers at ratios: of 4.5:1.5 (F1), 4:1 (F2), 3.5:1.5 (F3), 3:2 (F4), and 2.5:2.5 (F5). The total polymer weight for each formula was $500 \mathrm{mg}$. The compositions of the curcumin nanoparticles transdermal patches can be seen in table 1 .

PEG 400 was used as a plasticizer, and methol was used as a permeation enhancer. HPMC was dissolved in $15 \mathrm{ml}$ of a dichloromethane-ethanol mixture (1:1) using magnetic stirrer. EC and menthol were dissolved in $2 \mathrm{ml}$ of chloroform. The EC and menthol solution was then added to the HPMC solution and homogenized using a magnetic stirrer. PEG400 was then added to the mixture. Ten milligrams of curcumin nanoparticles were added to the solution, and the mixture was homogenized using magnetic 
stirrer for $10 \mathrm{~min}$ until the dope solution formed. Ten milliliters resulted solution was then poured into a plate and oven-dried at $30^{\circ} \mathrm{C}$ for $24 \mathrm{~h}$. The resulted patches were then taken and placed into desiccator for further evaluation.

Table 1:Transdermal patches compositions

\begin{tabular}{|c|c|c|c|c|c|}
\hline \multirow[t]{2}{*}{ Ingredients } & \multicolumn{5}{|c|}{ Formulation code } \\
\hline & F1 & F2 & F3 & F4 & F5 \\
\hline Curcumin nanoparticles (mg) & 10 & 10 & 10 & 10 & 10 \\
\hline HPMC (mg) & 450 & 400 & 350 & 300 & 250 \\
\hline $\mathrm{EC}(\mathrm{mg})$ & 50 & 100 & 150 & 200 & 250 \\
\hline PEG400 (\%) & 30 & 30 & 30 & 30 & 30 \\
\hline Menthol (\%) & 5 & 5 & 5 & 5 & 5 \\
\hline
\end{tabular}

\section{Physical characterization of transdermal patches}

\section{Organoleptic evaluation}

The organoleptic evaluation was conducted by observing the color, odor, and texture of the patches.

\section{pH evaluation}

The patches were cut $\left(1 \times 1 \mathrm{~cm}^{2}\right)$ and immersed into $1 \mathrm{ml}$ of distilled water for $2 \mathrm{~h}$ at room temperature. $\mathrm{pH}$ evaluation was performed by placing a universal indicator on the patches' surfaces for 1 minute. $\mathrm{pH}$ was then measured [8].

\section{Thickness uniformity}

Thickness uniformity was evaluated by a digital micrometer at three different points of patches in triplicate. The average thickness of the three points was then calculated [9].

\section{Weight uniformity}

For each formula, each of the three patches was weighed, and the average weight was then calculated [7].

\section{Percent of moisture content}

The percent of moisture content of the patches was evaluated by weighing the patches and then placed them into desiccator for $24 \mathrm{~h}$. After $24 \mathrm{~h}$ the patches were re-weighed. The percent moisture content was calculated by the following formula [10]:

$$
\text { Moisture content }(\%)=\frac{\text { Initial weight-Final weight }}{\text { Initial weight }} \times 100 \%
$$

\section{Tensile strength}

The tensile strength of the patches was determined by a tensile tester (Shimadzu Autograph AG-X, Japan). The patches tested were cut $4 \times 1 \mathrm{~cm}^{2}$ in size and placed between cell grips. Force was applied to the film until the film was broken. The tensile strength of the patches was determined from dial reading in $\mathrm{kg}$. The tensile strength of the patches was calculated by the following formula [8]:

$$
\text { Tensile strength }=\frac{\text { Tensile load at break }}{\text { Cross-section area }}
$$

\section{Permeation study}

A permeation study was conducted using back skin of rats. Rats were obtained from the Laboratory of Pharmacy Faculty, Halu Oleo University. The skin permeation study was performed by using modified Frans diffusion cells. The approval number of Ethical clearance for animal handling was 2498/UN29.20/PPM/2018. Animal experiments cages were made from plastic material with 40 $\mathrm{cm} \times 30 \mathrm{~cm} \times 12 \mathrm{~cm}$. The cages floor was applied with wood shavings (husks). The cage's top was protected with ram wire to prevent mice from coming out of the cage. Drink bottles and pellets were placed properly in the cages. The purpose of acclimatization is to adapt animals with their environment. Animal acclimation was exhibited for $7 \mathrm{~d}$ [11].

Fresh pieces of white rat skin were placed between donor and receptor compartments. The patches were placed above the skin. The receptor compartment was filled with $50 \mathrm{ml}$ of phosphate buffer solution at $\mathrm{pH} 7.4$ as the diffusion medium. The temperature of the medium was set at $37 \pm 0.5{ }^{\circ} \mathrm{C}$. The phosphate buffer solution was homogenized by magnetic stirrer at $200 \mathrm{rpm}$. At time intervals of 0,15 , $30,45,60,90,120,180,240,300$, and $350 \mathrm{~min}, 3 \mathrm{ml}$ of phosphate buffer solution was withdrawn and replaced with $3 \mathrm{ml}$ of fresh medium. The permeated curcumin in the acceptor compartment was analyzed by a UV VIS spectrophotometer (Jenway, UK) at $\lambda$ of $421 \mathrm{~nm}$.

\section{Drug release study}

A drug release study of the patches was conducted by the modified paddle over disk method (Erweka DT 820, Germany). The patches were placed in the aluminum disk. Five hundred of phosphate buffer solution at $\mathrm{pH} 7.4$ was used as a dissolution medium and stirred at $50 \mathrm{rpm}$. The temperature of the medium was maintained at $37 \pm 0.5{ }^{\circ} \mathrm{C}$. At time intervals $0,5,10,15,20,30,60,120,240$ and $360 \mathrm{~min}, 3 \mathrm{ml}$ of medium solution was taken and replaced with fresh medium in the same volume. The released curcumin was analyzed by a UV VIS spectrophotometer (Jenway, UK) at $\lambda$ of $421 \mathrm{~nm}$. The test was performed in triplicate.

\section{RESULTS}

\section{Physical characterization of transdermal patches}

The results of the organoleptic evaluation of the five formulas showed that all of the formulas generated a smooth surface texture, dry, elastic, yellow, menthol-odor, and transparent properties. The curcumin nanoparticles transdermal patches are shown in fig. 1. All of the physical characterizations of the transdermal patches, including the $\mathrm{pH}$, thickness uniformity, weight uniformity, percent moisture content, and tensile strength, are shown in table 2 and table 3 .

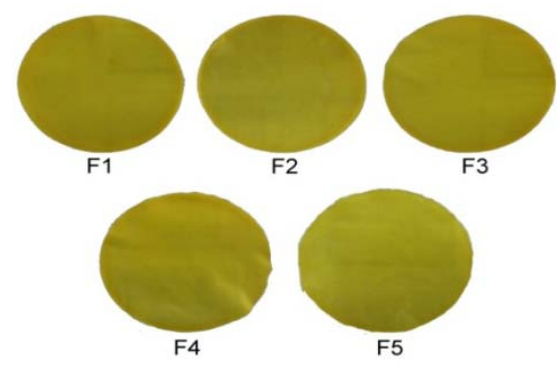

Fig. 1: Curcumin nanoparticles transdermal patches

Table 2: Physical characterization of transdermal patches

\begin{tabular}{llll}
\hline Formulation code & Thickness (mm) & Weight (g) & Moisture content (\%) \\
\hline F1 & $0.16 \pm 0.01$ & $0.77 \pm 0.02$ & $6.14 \pm 0.61$ \\
F2 & $0.17 \pm 0.01$ & $0.75 \pm 0.03$ & $5.60 \pm 0.72$ \\
F3 & $0.16 \pm 0.01$ & $0.74 \pm 0.01$ & $2.70 \pm 0.16$ \\
F4 & $0.21 \pm 0.01$ & $0.73 \pm 0.01$ & $1.61 \pm 0.61$ \\
F5 & $0.15 \pm 0.02$ & $0.76 \pm 0.02$ & $1.84 \pm 0.15$ \\
\hline
\end{tabular}

*mean $\pm \mathrm{SD}=$ Standard Deviation from the mean, $\mathrm{n}=3$ 
Table 3: Physical characterization of transdermal patches

\begin{tabular}{llll}
\hline Formulation code & pH & Tensile strength $\mathbf{~ N} / \mathbf{m m}^{2}$ ) & Elongation (\%) \\
\hline F1 & 5 & $2.35 \pm 0.01$ & $140 \pm 5$ \\
F2 & 5 & $2.25 \pm 0.03$ & $144 \pm 6$ \\
F3 & 6 & $1.60 \pm 0.05$ & $160 \pm 3$ \\
F4 & 6 & $1.43 \pm 0.02$ & $100 \pm 4$ \\
F5 & 5 & $2.31 \pm 0.01$ & $140 \pm 5$ \\
\hline
\end{tabular}

${ }^{*}$ mean $\pm \mathrm{SD}=$ Standard Deviation from the mean, $\mathrm{n}=3$

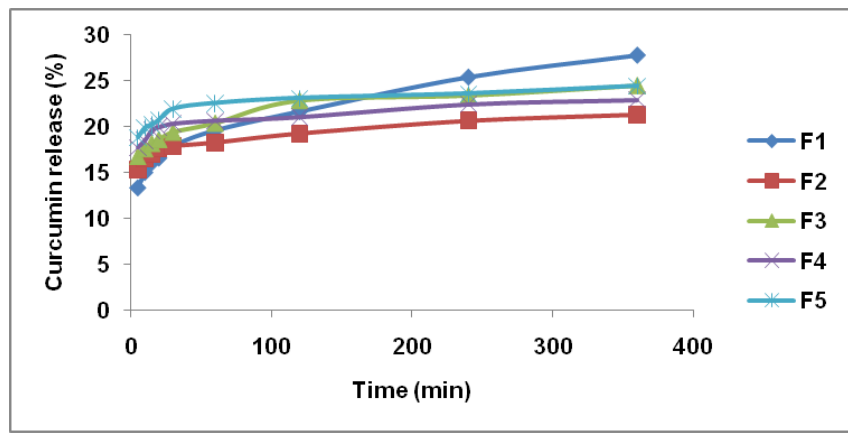

Fig. 2: Profile of theophylline release of curcumin from the transdermal patches

\section{Drug release study}

The results of the drug release study of the curcumin nanoparticles transdermal patches showed that at $360 \mathrm{~min}$ the curcumin release in F1 was higher than those in another formula. The curcumin release from the transdermal patches varied from $21.31 \%$ to $27.82 \%$ (fig. 2)

\section{Kinetic modeling of drug release}

The $\mathrm{R}^{2}$ values obtained from zero-order, first-order, Higuchi, Korsmeyer-Peppas and Hixson-Crowell models show that the curcumin release from the transdermal patches was best fitted to the Korsmeyer-Peppas model. The $\mathrm{R}^{2}$ values obtained in F1 to F5 by the Korsmeyer-Peppas model were 0.993, 0.978, 0.988, 0.956, and 0.965 , respectively (table 4).

\section{Permeation study}

The results of the skin permeation study of curcumin nanoparticles transdermal patches show that curcumin could penetrate into the skin with the percent transport of curcumin in F1 being higher than that in other formulas. The percentage of drug permeated in F1 to F5 at 360 min was $14.24 \%, 11.08 \%, 9.46 \%, 9.89 \%$, and $6.98 \%$, respectively (fig. 3). The flux values in F1 to F5 are tabulated in table 5.

Table 4: $\mathbf{R}^{2}$ values obtained from zero-order, first-order, higuchi, korsmeyer-peppas and hixson-crowell models

\begin{tabular}{lllll}
\hline Formulation code & $\mathbf{R}^{2}$ values & & & \\
\cline { 2 - 5 } & Zero-order & First-order & Higuchi & Korsmeyer-peppas \\
\hline F1 & 0.914 & 0.927 & 0.986 & 0.993 \\
F2 & 0.833 & 0.842 & 0.934 & 0.978 \\
F3 & 0.83 & 0.837 & 0.946 & 0.988 \\
F4 & 0.773 & 0.782 & 0.884 & 0.956 \\
F5 & 0.71 & 0.718 & 0.855 & 0.965 \\
\hline
\end{tabular}

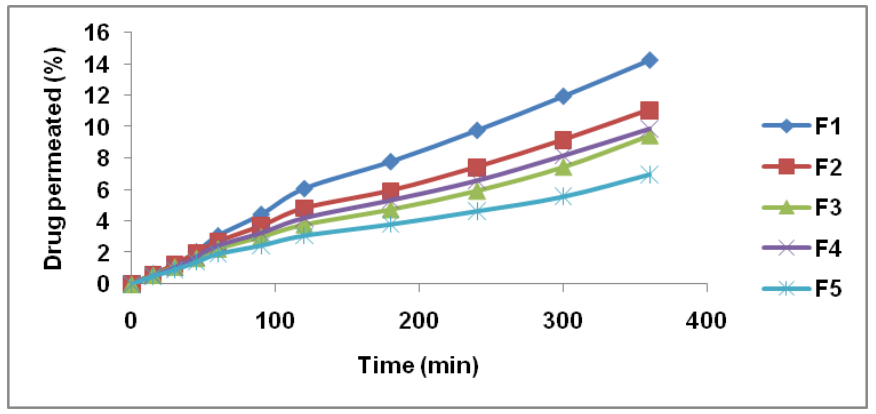

Fig. 3: Skin permeation study of the curcumin nanoparticles transdermal patches

Table 5: Flux values of the curcumin nanoparticles transdermal patches

\begin{tabular}{lllll}
\hline Parameter & F1 & F2 & F3 & F4 \\
\hline Flux $\left(\mu \mathrm{g} / \mathrm{cm}^{2}\right)$ & $1.271 \pm 0.012$ & $0.938 \pm 0.018$ & $0.775 \pm 0.022$ & $0.837 \pm 0.014$ \\
\hline
\end{tabular}

\footnotetext{
*mean $\pm \mathrm{SD}=$ Standard Deviation from the mean, $\mathrm{n}=3$
} 


\section{DISCUSSION}

One of the most important components in transdermal patches is polymer. In preparation for transdermal patches, hydrophilic polymers and hydrophobic polymers are combined at certain ratios to control the drug release and mechanical properties of the transdermal patches [12]. HPMC is a hydrophilic polymer that has been used in the preparation of transdermal patches. In addition, strong and flexible transdermal patches can be produced from the preparation of patches by HPMC as a polymer. Meanwhile, ethylcellulose is a hydrophobic polymer that is non-toxic and non-irritant and, when combined with HPMC will produce transdermal patches with better mechanical properties than when a single type of polymer is used. HPMC-EC is a common combination of polymers used in the preparation of transdermal patches and is compatible with a number of drugs [13].

Physical characterization of transdermal patches was performed for a number of parameters (organoleptic properties, thickness uniformity, weight uniformity, moisture content, $\mathrm{pH}$, tensile strength, and percent elongation). Uniformity of transdermal patches was shown in their organoleptic, thickness, weight, and $\mathrm{pH}$. The uniformity of the patches was shown by low standard deviation within the formulation. It indicates that the procedure is reproducible for transdermal patch formulation [14].

The weight of the transdermal patches ranged between $0.73 \mathrm{~g}$ and $0.77 \mathrm{~g}$. Formula 1 had a higher weight than the rest of the formulas. The difference in weight was influenced by the differences in the concentrations of HPMC and EC. Increasing the number of hydrophilic polymers such as HPMC directly caused an increase in the weight of the patch matrix formed [15]. HPMC as a hydrophilic polymer can absorb high humidity, which caused an increase in transdermal patch weight and concentration. The thickness of the transdermal patches ranged from $0.15-0.21 \mathrm{~mm}$. The thickness of the formulated transdermal patches fulfilled the requirement for a transdermal patch thickness of less than $1 \mathrm{~mm}$ [16]. The surface $\mathrm{pH}$ of the transdermal patches could affect the stability and comfortability of the use of the patches. The surface $\mathrm{pH}$ of the formulated transdermal patches lied in the $\mathrm{pH}$ range of the skin [17]. The results of the moisture content evaluation show minimal percentage values of formulated transdermal patches ranging from 1.61 to 6.14 , ensuring stability and protection from microbial contamination. Formula 1 had higher percent moisture content than other formulas. An increase in HPMC concentration increased the percent moisture content of the transdermal patches [7]. The tensile strength evaluation was conducted to determine the strength of the transdermal patches using various concentrations of the polymer. It also gave a percentage percent elongation values to find out about the mechanical and elastic properties of the transdermal patches. The tensile strength of the formulated transdermal patches ranged from 1.43 to $2.35 \mathrm{~N} / \mathrm{mm} 2$, while the percent elongation ranged from 100 to $160 \%$.

Curcumin release from the transdermal patches was evaluated to predict the reproducibility rate and duration of curcumin action in vivo [18]. Cumulative percent curcumin release from the transdermal patch at $360 \mathrm{~min}$ ranged from $21.31 \%$ to $27.82 \%$. It could be predicted that in $24 \mathrm{~h}$ all curcumin would be released from the transdermal patches, and it was found to be satisfactory for transdermal patches. The $\mathrm{R}^{2}$ values of the curcumin nanoparticles transdermal patches were evaluated by graphical method for zero order, first order, Higuchi, Korsmeyer-Peppas, and Hixson-Crowell models to predict the kinetic release of curcumin from the transdermal patches, and the $\mathrm{R}^{2}$ value closest to 1 was chosen as the best model for curcumin release from the transdermal patch. The curcumin release from transdermal patch showed the best fit to the Korsmeyer-Peppas model, also known as the Power Low [17]. The Power Low indicates the limitation of determining the release mechanism of curcumin from the transdermal patch.

A skin permeation study was conducted using modified Frans diffusion cells. The results show that curcumin nanoparticles could penetrate into rat skin. Formulating curcumin as nanoparticles from chitosan and tripolyphosphate can generate permeation enhancers for curcumin transport into the skin. Chitosan acts as a permeation enhancer by opening tight junction and facilitating both paracellular and transcellular transport.

\section{CONCLUSION}

Curcumin nanoparticles have been successfully formulated into transdermal patches using combinations of HPMC and EC at various ratios. Physical characterization of curcumin nanoparticles transdermal patches showed the uniformity of curcumin nanoparticle transdermal patches. Curcumin can be released from the transdermal patch and can be predicted that all curcumin will be released in $24 \mathrm{~h}$. Curcumin can penetrate into the skin and formulating curcumin nanoparticles. Overall findings from this research show that the limitation of oral curcumin administration can be solved by formulating curcumin into curcumin nanoparticles transdermal patches, especially for inflammation therapy.

\section{ACKNOWLEDGMENT}

The authors are thankful to all members of our patch research group (Rima Aprianti, Firda Rahmania Putri, Marganita Nur Hasanah, Dewi Astriyanti, Fadilla Syafrani, Wiwi Asriani, Sitti Munawarah, Nila Astuti, and Aisyah Saliha Anto) from Department of Pharmacy, Faculty of Pharmacy, Halu Oleo University, Indonesia.

\section{AUTHORS CONTRIBUTIONS}

All the authors have contributed equally

\section{CONFLICT OF INTERESTS}

\section{Declared none}

\section{REFERENCES}

1. Maheshwari RK, Singh AK, Gaddipati J, Srimal RC. Multiple biological activities of curcumin: a short review. In: Life Sci 2006;78:2081-7.

2. Bisht S, Feldmann G, Soni S, Ravi R, Karikar C, Maitra A, et al. Polymeric nanoparticle-encapsulated curcumin ("nano curcumin"): a novel strategy for human cancer therapy. J Nanobiotechnol 2007;5:1-18.

3. Sheth NS, Mistry RB. Formulation and evaluation of transdermal patches and to study the permeation enhancement effect of eugenol. J Appl Pharm Sci 2011;1:96-101.

4. Suryani, Halid NHA, Akib NI, Rahmanpiu R, Mutmainnah N. Preparation of curcumin nanoparticle by using reinforcement ionic gelation technique. In: AIP Conference Proceedings; 2017. p. 1838.

5. Mohammed MA, Syeda JTM, Wasan KM, Wasan EK. An overview of chitosan nanoparticles and its application in nonparenteral drug delivery. Pharmaceutics 2017;9:1-26.

6. Patel KN, Patel HK, Patel VA. Formulation and characterization of the drug in adhesive transdermal patches of diclofenac acid. Int J Pharm Pharm Sci 2012;41:296-9.

7. Chauhan SB, Naved T, Parvez N. Effect of hydrophilic and hydrophobic polymer matrix on the transdermal drug delivery of ethinylestradiol and medroxyprogesterone acetate. Int J Appl Pharm 2019;11:210-5.

8. Prajapati ST, Patel CG, Patel CN. Formulation and evaluation of transdermal patch of repaglinide. ISRN Pharm 2011;2011:1-9.

9. Kumar M, Chauhan AKR, Kumar S, Kumar A, Malik S. Design and evaluation of pectin based metrics for transdermal patches of meloxicam. J Pharm Res Heal Care 2010;2:244-7.

10. Anod HV, Gupta NV, Gowda DV, Manohar M. Preparation and evaluation of simvastatin transdermal film. Int J Appl Pharm 2018;10:235-8.

11. Deacon RMJ. Housing, husbandry, and handling of rodents for behavioral experiments. Nat Protoc 2006;1:936-46.

12. Chander Jhawat V, Saini V, Kamboj S, Maggon N. Transdermal drug delivery systems: approaches and advancements in drug absorption through the skin. Int J Pharm Sci Rev Res 2013;20:47-56.

13. Ravi G, Vishal Gupta N. Development and evaluation of transdermal film containing solid lipid nanoparticles of rivastigmine tartrate. Int J Appl Pharm 2017;9:85-90.

14. Jayaprakash S, Mohamed Halith S, Mohamed Firthouse PU, Yasmin, Nagarajan M. Preparation and evaluation of celecoxib transdermal patches. Pak J Pharm Sci 2010;4:1824-34.

15. Tiwari SB, Murthy TK, Pai MR, Mehta PR, Chowdary PB. Controlled release formulation of tramadol hydrochloride 
using hydrophilic and hydrophobic matrix system. AAPS PharmSciTech 2003;4:1-6.

16. Singh A, Bali A. Formulation and characterization of transdermal patches for controlled delivery of duloxetine hydrochloride. J Anal Sci Technol 2016;7:1-13.
17. Sowjanya R, Duraivel S, Sampath Kumar KP, Debjit B. Formulation and evaluation of transdermal patches of carvedilol. J Chem Pharm Sci 2013;27:196-202.

18. Saravanakumar K, Swapna P, Nagaveni P, Vani P, Pujitha K. Transdermal drug delivery system: a review. J Global Trends Pharm Sci 2015;1:70-81. 